\title{
Dissociative experiences and interrogative suggestibility in college students
}

Citation for published version (APA):

Merckelbach, H. L. G. J., Muris, P. E. H. M., Rassin, E. G. C., \& Horselenberg, R. (2000). Dissociative experiences and interrogative suggestibility in college students. Personality and Individual Differences, 29, 29-29. https://doi.org/10.1016/S0191-8869(99)00260-3

Document status and date:

Published: 01/01/2000

DOI:

10.1016/S0191-8869(99)00260-3

Document Version:

Publisher's PDF, also known as Version of record

\section{Please check the document version of this publication:}

- A submitted manuscript is the version of the article upon submission and before peer-review. There can be important differences between the submitted version and the official published version of record. People interested in the research are advised to contact the author for the final version of the publication, or visit the DOI to the publisher's website.

- The final author version and the galley proof are versions of the publication after peer review.

- The final published version features the final layout of the paper including the volume, issue and page numbers.

Link to publication

\footnotetext{
General rights rights.

- You may freely distribute the URL identifying the publication in the public portal. please follow below link for the End User Agreement:

www.umlib.nl/taverne-license

Take down policy

If you believe that this document breaches copyright please contact us at:

repository@maastrichtuniversity.nl

providing details and we will investigate your claim.
}

Copyright and moral rights for the publications made accessible in the public portal are retained by the authors and/or other copyright owners and it is a condition of accessing publications that users recognise and abide by the legal requirements associated with these

- Users may download and print one copy of any publication from the public portal for the purpose of private study or research.

- You may not further distribute the material or use it for any profit-making activity or commercial gain

If the publication is distributed under the terms of Article $25 \mathrm{fa}$ of the Dutch Copyright Act, indicated by the "Taverne" license above, 


\title{
Dissociative experiences and interrogative suggestibility in college students
}

\author{
Harald Merckelbach*, Peter Muris, Eric Rassin, Robert Horselenberg \\ Department of Psychology, Maastricht University, PO Box 616, 6200 MD, Maastricht, The Netherlands \\ Received 5 March 1999; received in revised form 29 October 1999; accepted 13 December 1999
}

\begin{abstract}
The present study examined whether scores on the Dissociative Experiences Scale (DES) are related to interrogative suggestibility, as measured by the Gudjonsson Suggestibility Scale (GSS-1). In addition, an attempt was made to identify factors that may mediate this relationship. The DES and GSS were administered to a sample of 56 female undergraduate students along with self-report measures of cognitive failures and fantasy proneness. DES and cognitive failures were found to be related to total GSS scores. In contrast, fantasy proneness was not linked to total GSS scores. Correcting for the influence of cognitive failures attenuated the correlation between DES and GSS. This suggests that cognitive efficiency is one of the mediating factors operating in the connection between dissociation and interrogative suggestibility. (C) 2000 Elsevier Science Ltd. All rights reserved.
\end{abstract}

Keywords: Dissociative experiences; DES; Suggestibility; Cognitive failures; Fantasy proneness

\section{Introduction}

The concept of dissociation refers to a wide variety of experiences and sensations. For example, derealization, depersonalization, memory disturbances, and identity confusion have all been considered as manifestations of dissociation. A number of authors have argued that elevated levels of dissociation are a direct consequence of a traumatic childhood history. More specifically, these authors argue that dissociation is best conceptualized as a defense mechanism

\footnotetext{
* Corresponding author. Tel.: + 31-43-3881945; fax: + 31-43-3615735.

E-mail address: h.merckelbach@psychology.unimaas.nl (H. Merckelbach).
} 
against traumatic memories (e.g., Ross, 1997). Support for this view comes from studies that found a connection between high levels of dissociation and self-reports of traumatic childhood events (e.g., Sanders \& Giolas, 1991; Nijman et al., 1999). In order to measure the degree to which participants experience dissociative phenomena, the majority of these studies relied on the Dissociative Experiences Scale (DES; Bernstein, \& Putnam, 1986). Meanwhile, there is some debate as to what the DES actually measures. It is widely believed that high DES scores point in the direction of certain psychopathological conditions, notably conditions that are thought to have a traumatic etiology (e.g., dissociative identity disorder; Ross, 1997). Yet, some authors contend that many DES items refer to benign characteristics such as fantasy proneness and lack of cognitive efficiency (Frankel, 1990; Hacking, 1995). To the extent that this view is correct, an interpretation of high DES scores in terms of unique and trauma-linked defenses becomes more problematic. Recent non-clinical studies indeed found positive connections between DES scores and measures of fantasy proneness (e.g., Rauschenberg \& Lynn, 1995) and cognitive efficiency (e.g., Merckelbach, Muris, \& Rassin, 1999). This suggests that at least in non-clinical samples, the dissociative experiences tapped by the DES do not represent a distinct and unique group of phenomena. Rather, these phenomena seem to be closely tied to the non-pathological traits of fantasy proneness and lack of cognitive efficiency (i.e., cognitive failures).

A detailed analysis of the correlates of the DES is important because it may shed a different light upon the well-established fact that high dissociators more often report psychiatric complaints and traumatic childhood events than do low dissociators (Merckelbach, Muris, Horselenberg, \& Stougie, 2000). For example, the robust correlation between DES and selfreported rates of daily slips and lapses may reflect high dissociators' reduced confidence in their own cognitive efficiency (e.g., their ability to retrieve accurate memories). Such a reduced confidence could increase a person's receptivity to misleading cues provided by others (Gudjonsson, 1996). If this line of reasoning is correct, caution is warranted in interpreting high dissociators' self-reports of traumatic childhood events, especially when these self-reports have been collected in a suggestive context.

Thus, it would be highly informative to examine the connection between dissociation and suggestibility. The type of suggestibility that seems to be most relevant in this context is what Gudjonsson (1996) has termed "interrogative suggestibility". Interrogative suggestibility is defined as "the extent to which, within a closed social interaction, people come to accept messages communicated during formal questioning, as the result of which their subsequent behavioural response is affected" (Gudjonsson, 1996; p. 115). The Gudjonsson Suggestibility Scale (GSS; Gudjonsson, 1997a) is a well-researched instrument to measure this type of suggestibility. This scale taps two different aspects of interrogative suggestibility, namely susceptibility to misleading information (i.e., Yield) and the tendency to change responses under conditions of social pressure (i.e., Shift). So far, only one study (Wolfradt \& Meyer, 1998) systematically looked at the connection between dissociation and interrogative suggestibility. In that study, the DES and GSS were administered to a sample of anxiety disordered patients and normal controls. A correlation of 0.54 between dissociation and total suggestibility scores was found for the entire sample. For normal control participants, the correlation between DES and GSS was primarily carried by the Yield-subscale of the GSS. That is, in this subsample, DES was significantly related to susceptibility to misleading 
information (i.e., Yield), but not to the tendency to shift response under social pressure (i.e., Shift).

The current study further examined the links between dissociation and interrogative suggestibility. More specifically, the study sought to replicate the findings of Wolfradt and Meyer (1998). In addition, it addressed the issue of whether self-reported cognitive efficiency may operate as mediating variable between dissociation and suggestibility.

\section{Method}

\subsection{Participants}

The sample consisted of 56 women who volunteered to participate in the study. Their mean age was 18.5 years (range: 17-22 years). Participants were undergraduate psychology students at Maastricht University. They received a small financial compensation for completing a set of questionnaires (see below). Participants were tested individually.

\subsection{Questionnaires}

\subsubsection{Dissociation Experiences Scale}

The Dissociative Experiences Scale (DES; Bernstein \& Putnam, 1986; Cronbach's alpha $=0.89)$ is a self-report instrument containing 28 items that describe dissociative phenomena such as disturbances in memory, awareness, and cognition. An illustrative item is: "Some people have the experience of driving a car and suddenly realizing that they don't remember what has happened during all or part of the trip. Mark the line to show what percentage of the time this happens to you". Participants indicate on 100-mm visual analog scales the frequency with which they experience the phenomena described by the items (anchors: $0=$ not at all; $100=$ very much). Scores are averaged across items to obtain a mean DES score. A large number of studies have found support for the psychometric qualities of the DES (Van IJzendoorn \& Schuengel, 1996). That is, the DES possesses excellent internal consistency and test-retest stability (e.g., Bernstein \& Putnam, 1986).

\subsubsection{Cognitive Failures Questionnaire}

The Cognitive Failures Questionnaire (CFQ; Broadbent, Cooper, Fitzgerald, \& Parkes, 1982; Cronbach's alpha $=0.84$ ) is a 25 -item self-report instrument that measures the frequency of everyday lapses and minor blunders (e.g., "Do you forget appointments?"). Subjects indicate on a 5-point scale how often they have experienced each cognitive failure in the past month (anchors: $0=$ never; $4=$ very often). Scores are summed to obtain a total CFQ score. Merckelbach, Muris, Nijman, and De Jong (1996) provided evidence that underlines the good psychometric qualities of the Dutch CFQ.

\subsubsection{The Creative Experiences Questionnaire}

The Creative Experiences Questionnaire (CEQ; Merckelbach, Muris, Schmidt, Rassin, \& Horselenberg, 1998a; Cronbach's alpha $=0.72$ ) is a 25 -item measure of fantasy proneness that 
is scaled in the true/false form. CEQ items were derived from the extensive case descriptions of fantasy proneness provided by Wilson and Barber (1983). Typical examples are: "In general, I spend at least half of the day fantasizing or daydreaming" and "My fantasies are so vivid that they are like a good movie". The number of yes-answers is summed to yield a total CEQ score. There is solid evidence for the reliability and validity of the CEQ (Merckelbach et al., 1998a).

\subsubsection{The Gudjonsson Suggestibility Scale}

A Dutch translation of the Gudjonsson Suggestibility Scale (GSS-1; Gudjonsson, 1997a) was used in the current study. The GSS consists of a short story that is read out to the participant, who then reports all he or she recalls about the story (immediate free recall). One point is given for each correctly reproduced detail of the story. The story contains 40 distinct elements, so that the maximum score for free recall is 40 . Next, participants are asked 20 questions about the story, 15 of them being misleading. The extent to which participants give in to the misleading items is scored as Yield (Cronbach's alpha $=0.77$; maximum score $=15$ ). Following this, participants are told in an authoritative manner that they made many mistakes and that the questions are asked for a second time. The number of times that participants change their answer constitutes the Shift-score (Cronbach's alpha $=0.73$; maximum score $=20$ ). Yield- and Shift-scores are summed to yield a total suggestibility score (Cronbach's alpha $=0.75$; maximum score $=35$ ). A number of studies have demonstrated that the GSS-1 possesses adequate reliability, test-retest stability, and validity (for reviews see, Gudjonsson, 1996, 1997a). The study by Merckelbach, Muris, Wessel, and Van Koppen (1998b) found preliminary evidence to suggest that the psychometric properties of the Dutch translation of the GSS-1 are satisfactory. It should be added, though, that for practical reasons, the GSS procedure followed in the current study deviated from that recommended by Gudjonsson (1997a). That is, no delayed recall of the GSS story was obtained and Yield and Shift data were collected after a short interval that followed the immediate recall. During that interval, participants completed the CFQ and CEQ, while the DES was administered before participants heard the GSS story. Completion of the tests took about $30 \mathrm{~min}$.

\section{Results}

Table 1 presents descriptive statistics for the measures. Mean scores on the DES, CFQ and CEQ are well in line with those obtained in our previous studies (Merckelbach et al., 1996, 1998b, 1999, 2000). Mean Yield, Shift and Total suggestibility scores on the GSS are also within the normal range (see Appendix 5 in Gudjonsson, 1997a). On the other hand, free recall is unexpectedly low when it is compared to the normative data provided by Gudjonsson (1997a).

Table 2 shows Pearson product-moment correlations between DES, CFQ, and CEQ, on the one hand, and the GSS-1 measures (free recall, Yield, Shift, total suggestibility), on the other hand. As can be seen, DES correlated significantly with self-reported cognitive failures and fantasy proneness (CFQ and CEQ, respectively). Furthermore, there was a positive association between DES and total suggestibility scores. This correlation was carried by the DES-Yield 
Table 1

Mean, standard deviations and range on dissociation (DES), cognitive failures (CFQ), fantasy proneness (CEQ), free recall, confabulation, yield, shift, and total score of the Gudjonsson Suggestibility Scale (GSS) $(N=56)$

\begin{tabular}{lccc}
\hline Test & Mean & SD & Range \\
\hline DES & 20.9 & 10.7 & $2.2-48.8$ \\
CFQ & 44.9 & 11.2 & $20-73$ \\
CEQ & 8.8 & 3.9 & $2-17$ \\
Free recall & 16.2 & 4.5 & $6.1-26.5$ \\
Yield & 3.3 & 2.2 & $0-12$ \\
Shift & 4.5 & 2.6 & $0-12$ \\
Total suggestibility & 7.8 & 3.6 & $2-20$ \\
\hline
\end{tabular}

rather than the DES-Shift connection. Also, DES and free recall of the GSS correlated negatively.

CFQ and CEQ did not correlate with each other. As to the connection between cognitive failures and suggestibility, the correlations between CFQ and Shift and total suggestibility attained significance. In contrast, the correlations between fantasy proneness and GSS measures all failed to reach significance.

To explore to what extent the connections between DES and interrogative suggestibility are mediated by cognitive failures, a set of partial correlations were computed. The correlation between DES and total suggestibility reached only borderline significance (partial $r=0.25, p=$ 0.07) when the influence of CFQ was partialled out. The same was true for the partial correlation between DES and free recall. That is, controlling for CFQ lead to a borderline significant correlation between these measures (partial $r=-0.25, p=0.07$ ). The correlation between DES and Yield disappeared when controlling for CFQ (partial $r=0.20, p=0.15$ ).

\section{Discussion}

The results of the current study can be catalogued as follows. To begin with, dissociation

Table 2

Pearson correlations between dissociation (DES), cognitive failures (CFQ), fantasy proneness (CEQ), and GSS measures (i.e., free recall, Yield, Shift, and total suggestibility) $(N=56)$

\begin{tabular}{|c|c|c|c|}
\hline & $\mathrm{DES}^{\mathrm{a}}$ & $\mathrm{CFQ}^{\mathrm{a}}$ & CEQ \\
\hline CFQ & $0.42^{* *}$ & & \\
\hline CEQ & $0.48^{* *}$ & 0.18 & \\
\hline Free recall & $-0.30^{*}$ & -0.19 & -0.14 \\
\hline Yield & $0.29^{*}$ & 0.25 & 0.00 \\
\hline Shift & 0.22 & $0.27^{*}$ & 0.07 \\
\hline Total suggestibility & $0.37^{* *}$ & $0.36^{* *}$ & 0.05 \\
\hline
\end{tabular}

\footnotetext{
a ${ }^{*} p<0.05 ;{ }^{* *} p<0.01 ;$ (two-tailed).
} 
had low but significant correlations with certain aspects of interrogative suggestibility. More specifically, the stronger the propensity for dissociative experiences as assessed by the DES, the stronger the tendency to give in to misleading information (Yield) and the higher the total suggestibility score. The finding that dissociation is related to the Yield rather than the Shift dimension of interrogative suggestibility replicates the results of previous studies. That is, both Wolfradt and Meyer (1998) and Merckelbach et al. (1998b) noted that the association between DES and total suggestibility scores on the GSS was carried by the Yield dimension of the GSS. Taken together, these results converge upon the conclusion that dissociation is related to one particular feature of interrogative suggestibility, namely vulnerability to post-hoc misinformation.

Second, like previous studies (Merckelbach et al., 1998b, 1999, 2000), the current study found dissociation to be closely related to self-reported cognitive failures and fantasy proneness. And like these previous studies, cognitive failures and fantasy proneness were not associated with each other, indicating that both traits are independent correlates of dissociation.

Third, controlling for the influence of cognitive failures reduced the correlation between dissociation and GSS Yield to a non-significant level. This suggests that a (self-reported) lack of cognitive efficiency, at least in part, mediates the connection between dissociation and receptivity to misleading information. From a theoretical point of view, this makes sense. Of particular importance in this context is that DES and CFQ both comprise a number of items that allude to memory failures. Thus, individuals who score high on these items will not have much confidence in their own memory capability and, therefore, will more readily rely on (misleading) information suggested by others (e.g., Gudjonsson, 1997b). This line of reasoning is further supported by the finding that DES correlated negatively with free recall of the GSS story, a correlation that also attenuated when the influence of the CFQ was controlled for. In more general terms, the links between dissociation, self-reported cognitive failures and suggestibility accord well with earlier studies indicating that feelings of incompetence may contribute to suggestibility (for a review see Gudjonsson, 1996).

Fourth, fantasy proneness did not correlate with any of the measures derived from the GSS. This finding is reminiscent of the idea that there are two types of suggestibility: hypnotic suggestibility which involves absorption and fantasy proneness, on the one hand, and interrogative suggestibility as indexed by the Yield and Shifts scales of the GSS, on the other hand (e.g., Gudjonsson, 1996, 1997b). Clearly, DES is connected to both types of suggestibility, while these two types do not necessarily correlate with each other. It should be noted that the current study focused on the links between the capacity for dissociation and the Yield and Shift aspects of the GSS. Yet, the GSS also allows for the quantification of confabulatory responding during free recall. It might well be the case that fantasy proneness is connected to this GSS parameter (e.g., Ost, Fellows, \& Bull, 1997; Merckelbach et al., 2000). Normative data collected by Gudjonsson (1997a) show that confabulatory responding during GSS free recall is a phenomenon with a relatively low base rate in the normal population. There are also indications that this GSS parameter is considerably more difficult to measure compared to the Yield and Shift parameters (Gudjonsson \& Sigurdsson, 1996; Smith \& Gudjonsson, 1995). The current study relied on a relatively small and non-clinical sample. Given these features, it did not provide a good opportunity for testing the connections between 
DES, fantasy proneness, and confabulatory responding on the GSS. Clearly, this point needs to be addressed by future studies relying on large and preferably clinical samples.

Another limitation of our sample was that it consisted of undergraduate women. It remains to be seen to what extent the present findings can be generalized to men and, more importantly, to clinical samples. Furthermore, the current study administered the GSS in a way that deviated from the procedure recommended by Gudjonsson (1997a). More specifically, the Yield and Shift measures were not obtained directly after GSS free recall and the various GSS elements were embedded in a series of other scales (i.e., DES, CFQ, and CEQ). Combined with the characteristics of our sample, this may have contributed to unexpectedly low free recall performance. While the average free recall score found in the present study was comparable to the mean (GSS-2) free recall score reported by Wolfradt and Meyer (1998) for their normal sample, it is conceivable that our undergraduate sample used conservative criteria for free recall reproduction, thereby producing an underestimation for their memory capacity.

To sum up, then, the current study found a modest, but significant connection between dissociation and the tendency to accept misleading information. In addition, evidence was found to support the notion that self-reported cognitive efficiency plays a mediating role in the link between DES and suggestibility. The current results may help explain why some studies found the DES to be a powerful predictor of autobiographical memory distortion (e.g., Hyman \& Billings, 1998), while other studies failed to replicate this phenomenon (e.g., Platt, Lacey, Iobst, \& Finkelman, 1998). The critical difference between these studies might be the absence or presence of suggestive techniques to induce memory distortions. That is, the connection between DES and interrogative suggestibility found in our study seems to indicate that studies using suggestive maneuvers to induce pseudomemories will be more successful in detecting a connection between DES and autobiographical memory distortion than studies examining the more or less spontaneous memory distortions that develop over time (Platt et al., 1998).

Future research should examine the causal mechanisms that underlie the connections between dissociation, self-reported cognitive failures, and fantasy proneness. One possibility is that a history of aversive childhood events acts as a major developmental cause of these characteristics (e.g., Lawrence, Edwards, Barraclough, Church, \& Hetherington, 1995). Another possibility is that the fantasy proneness and suggestibility implicated by the correlates of the DES are conductive to self-reports of trauma (e.g., Merckelbach et al., 2000; Merckelbach \& Muris, in press). Of course, less streamlined models that involve more complex interactions between dissociation, fantasy proneness, and self-reported cognitive failures are also possible. A covariance structure modeling study of the type described by Lawrence et al. (1995) might provide a preliminary test of these possibilities.

\section{References}

Bernstein, E. M., \& Putnam, F. W. (1986). Development, reliability, and validity of a dissociation scale. Journal of Nervous and Mental Disease, 174, 727-735.

Broadbent, D. E., Cooper, P. F., Fitzgerald, P., \& Parkes, L. R. (1982). The cognitive failures questionnaire (CFQ) and its correlates. British Journal of Clinical Psychology, 21, 1-16.

Frankel, F. H. (1990). Hypnotizability and dissociation. American Journal of Psychiatry, 147, 823-829.

Gudjonsson, G. H. (1996). The psychology of interrogations, confessions, and testimony. Chichester: Wiley. 
Gudjonsson, G. H. (1997a). The Gudjonsson suggestibility scales manual. Hove: Psychology Press.

Gudjonsson, G. H. (1997b). False memory syndrome and the retractors: Methodological and theoretical issues. Psychological Inquiry, 8, 296-299.

Gudjonsson, G. H., \& Sigurdsson, J. F. (1996). The relationship of confabulation to the memory, intelligence and personality of prison inmates. Applied Cognitive Psychology, 10, 85-92.

Hacking, I. (1995). Rewriting the soul: Multiple personality and the sciences of memory. New Jersey: Princeton.

Hyman, I. E., \& Billings, F. J. (1998). Individual differences and the creation of false memories. Memory, 6, 1-20.

Lawrence, T., Edwards, C., Barraclough, N., Church, S., \& Hetherington, F. (1995). Modelling childhood causes of paranormal belief and experience: Childhood trauma and childhood fantasy. Personality and Individual Differences, 19, 209-215.

Merckelbach, H., \& Muris, P. (in press). The causal link between self-reported trauma and dissociation: A critical review. Behaviour Research and Therapy.

Merckelbach, H., Muris, P., Nijman, H., \& De Jong, P. J. (1996). Self-reported cognitive failures and neurotic symptomatology. Personality and Individual Differences, 20, 715-724.

Merckelbach, H., Muris, P., Horselenberg, R., \& Stougie, S. (2000). Dissociative experiences, response bias, and fantasy proneness in college students. Personality and Individual Differences, 28, 49-58.

Merckelbach, H., Muris, P., Rassin, \& E (1999). Fantasy proneness and cognitive failures as correlates of dissociative experiences. Personality and Individual Differences, 26, 961-967.

Merckelbach, H., Muris, P., Schmidt, H., Rassin, E., \& Horselenberg, R. (1998a). De Creatieve Ervaringen Vragenlijst als maat voor "fantasy proneness" (The Creative Experiences Questionnaire (CEQ) as a measure of fantasy proneness). De Psycholoog, 33, 204-208.

Merckelbach, H., Muris, P., Wessel, I., \& Van Koppen, P. J. (1998b). The Gudjonsson Suggestibility Scale (GSS): Further data on its reliability, validity, and metacognition correlates. Social Behavior and Personality, 26, 203210.

Nijman, H., Dautzenberg, M., Merckelbach, H., Jung, P., Wessel, I., \& Campo, J. (1999). Self-mutilating behavior of psychiatric inpatients. European Psychiatry, 14, 4-10.

Ost, J., Fellows, B., \& Bull, R. (1997). Individual differences and the suggestibility of human memory. Contemporary Hypnosis, 14, 132-137.

Platt, R. D., Lacey, S. C., Iobst, A. D., \& Finkelman, D. (1998). Absorption, dissociation, and fantasy-proneness as predictors of memory distortion in autobiographical and laboratory-generated memories. Applied Cognitive Psychology, 12, 77-89.

Rauschenberg, S. L., \& Lynn, S. J. (1995). Fantasy proneness, DSM-III-R axis I psychopathology, and dissociation. Journal of Abnormal Psychology, 104, 373-380.

Ross, C. A. (1997). Dissociative identity disorder: Diagnosis, clinical features, and treatment of multiple personality. New York: Wiley.

Sanders, B., \& Giolas, M. H. (1991). Dissociation and childhood trauma in psychologically disturbed adolescents. American Journal of Psychiatry, 148, 50-54.

Smith, P., \& Gudjonsson, G. H. (1995). Confabulation among forensic inpatients and its relationship with memory, suggestibility, compliance, anxiety, and self-esteem. Personality and Individual Differences, 19, 517-523.

Van Ijzendoorn, M. H., \& Schuengel, C. (1996). The measurement of dissociation in normal and clinical populations: Meta-analytic validation of the Dissociative Experiences Scale (DES). Clinical Psychology Review, $16,365-382$.

Wilson, S. C., \& Barber, T. X. (1983). Fantasy-prone personality: Implications for understanding imagery, hypnosis, and parapsychological phenomena. In A. A. Sheikh, Imagery: Current Theory, Research, and Application (pp. 340-387). New York: Wiley.

Wolfradt, U., \& Meyer, T. (1998). Interrogative suggestibility, anxiety and dissociation among anxious patients and normal controls. Personality and Individual Differences, 25, 425-432. 